\title{
Congenital Metabolic Disorder
}

National Cancer Institute

\section{Source}

National Cancer Institute. Congenital Metabolic Disorder. NCI Thesaurus. Code C34816.

A group of disorders present at birth that involve genetic defects leading to disturbances in carbohydrate, lipid, lysosomal storage or amino acid metabolism in the body. 